\title{
Self-destruction and countertransference reactions in adolescent psychotherapy: a psychoanalytic case
}

\section{report}

\begin{abstract}
Self-destruction behaviors in adolescents constitute a serious mental health problem. Several psychoanalysts and psychodynamic theorists have long attempted to understand the desire of self-destruction. Suicidal adolescents often elicit strong countertransference reactions from therapists. These reactions fluctuate from the belief that the therapist should be the perfect object that will relieve the suffering teenager to the openly hostile stance by the therapist. The awareness and working-through of representations and emotions produced by the patient in the analyst's mind facilitates further understanding of transference phenomena. The present psychoanalytic case report of a suicidal adolescent tries to illustrate some aspects of these complex reactions. The psychodynamic approaches can contribute significantly to the diagnostic access and the treatment of adolescents after a suicide attempt.
\end{abstract}

Keywords: adolescence, countertransference, psychoanalytic psychotherapy, suicide attempt
Volume I Issue 4 - 2014

\author{
George Giannakopoulos, Kalliopi \\ Triantafyllou, Stylianos Christogiorgos \\ Department of Child Psychiatry, University of Athens Medical \\ School, Greece
}

\begin{abstract}
Correspondence: George Giannakopoulos, Department of Child Psychiatry, University of Athens Medical School, Aghia Sophia Children's Hospital,Thivon and Papadiamantopoulou I I 527 Athens, Greece, Tel 302 I074738I, Fax 00302 I074738I, Email Giannakopoulos.med@gmail.com
\end{abstract}

Received: June 23, 2014 | Published: July II, 2014

\section{Introduction}

Self-destruction behaviors in adolescents constitute a serious mental health problem, with approximately $80 \%$ of suicidal thoughts and attempts present in adolescents struggling with a psychiatric disorder. ${ }^{1,2}$ Depression, substance use, borderline personality traits and dissociative symptoms or disorders have been identified as the major proximal risk factors for self-destruction behaviors in empirical studies with adolescents. ${ }^{3,4}$ In fact, some empirically-tested models propose that although substance use, borderline or dissociative symptoms are used as defenses against painful affects, they eventually facilitate self-destruction thoughts or acting out through the enhancement of impulsivity, affect dysregulation, splitting of the self and others, numbing of consciousness, depersonalization, and derealization.

Several psychoanalysts and psychodynamic theorists have long attempted to understand the desire of self-destruction. Freud ${ }^{6}$ considered suicide as a form of aggression associated with others and directed toward oneself. He argued that the ego can kill itself only if it can treat it as an object - when it can direct against itself the hostility which is associated with an object and which represents the ego's original reaction to objects in the external world. The lost or disappointing object is identified with and the ego becomes the target of aggressive wishes. Thus, Freud linked suicide to sadism redirected toward the self. Sadism was considered by Freud ${ }^{7}$ as a manifestation of the death instinct or the instinct of mastery, the desire to dominate and control the object. ${ }^{8-10}$ Indeed, the role of sadism turned inward has been supported by a recent empirical study in a nonclinical sample showing that sadistic traits explained unique variance in suicidality among adolescents. ${ }^{11}$ Freud ${ }^{12}$ later in his writings proposed that the superego fulfills the same protection and rescue function that before was fulfilled by the mother. However, when the ego is in so really great danger that it feels unable to overcome alone, it sees itself as deserted by all protective forces and left to die. Additionally, Fenichel ${ }^{13}$ suggested that the ego either submits to the protecting aspects of the superego for forgiveness and reconciliation, or the ego expresses rebellious rage against the superego and wishes to destroy it.

Within a relational context, the aggression toward the self represents an act of retaliatory abandonment against objects that have been lost or have threatened to leave and serves to restore a threatened relationship via repentant self-punishment. ${ }^{14,15}$ Kohut $^{16}$ studied the process of collapse of self that leads to suicide. He wrote that the suicidal patients have not adequately satisfied the narcissistic needs during development and that leads to a poorly developed sense of self. When others are frustrated, the result is a narcissistic injury through which the person experiences a deep sense of loss, a threat to its integrity and a deep, unbearable, disruptive anxiety. In his megalomania, the suicidal patient believes that suicide is a means to escape from this intense discomfort and a means to control or defeat death. Self-destruction then constitutes a reaction to narcissistic rage, shame or other forms of aversive self-awareness. ${ }^{17}$

Object relations theorists regard self-destruction as an attempt, in fantasy, to destroy bad internal objects - introjects - or undesirable aspects of the self. ${ }^{18}$ Klein ${ }^{19}$ argued that suicide is not only the symbolic death of the evil object, but also the maintenance of the bonds with its beloved object. Also, Winnicott ${ }^{20,21}$ claimed that suicide involved a fantasy of destroying bad aspects of the self with the remainder of the self surviving, or as a destruction the entire self when the true self is threatened with exploitation or annihilation. Suicidal individuals often evidence few positive soothing introjects and poorly integrated hostile introjects, and they enact interpersonally and project these pathological internal object relations. ${ }^{22,23}$ A common type of object relationship with these patients, projective identification, can be conceptualized as a process involving three phases: first, the fantasy of ridding oneself of an unwanted part of the self and of putting that part into another person in a controlling way; then there is a pressure exerted by means of interpersonal interaction such that the recipient of the projection experiences pressure to think, feel, and behave in a manner congruent with the projection; finally, the projected feelings 
are reinternalized by the projector, after being psychologically processed by the recipient. ${ }^{24}$ Empirical studies that aimed at testing the object-relational view of suicidal behavior concluded that objectloss (i.e. a more significant history of past and recent losses) could better explain suicidal behavior than self-targeted anger, maladaptive defenses or primitive object representations..$^{25,26}$

From an ego functioning theoretical perspective, King and Apter ${ }^{27}$ described three common themes that occur in adolescents after a suicide attempt. First, adolescents who have attempted suicide perceive their parents as indifferent to their physical existence and extremely judgmental. Second, suicidal adolescents do not have an adequate capability for self-relief or tolerance of painful feelings. According to Freud, ${ }^{28}$ this is indicative of deficient internalized objects that are incapable to provide relief. Moreover, the internalized indifferent object has a persecutory component through which the inconsolable self is experienced as evil and deserving punishment. Third, the lack of self-care is associated with a tendency to depression. In these cases the adolescent is vulnerable to suicidal impulses due to an extremely strict superego that punishes him for failing to reach his expectations. Through feelings of depression, the adolescent easily evades situations where he feels inadequate and this evasion reinforces the feeling of failure by directing aggressive impulses towards him.

Suicidal adolescents often elicit strong countertransference reactions from therapists. These reactions fluctuate from the belief that the therapist should be the perfect object that will relieve the suffering teenager to the openly hostile stance by the therapist. The awareness and working-through of representations and emotions produced by the patient in the analyst's mind facilitates further understanding of transference phenomena. ${ }^{29,30}$ Apart from facilitating the understanding of transference, another component of countertransference conceals aspects of transference. These two components are integrate $d^{25}$ into a single psychic activity, which is set out by the analyst as a response to his or her transference movements. Thus, every therapeutic situation is addressed and functions within the transference-countertransference space that is created. Within this framework, the particular characteristics of the therapeutic situation operate on any occasion. The following psychoanalytic case report of a suicidal adolescent tries to illustrate some aspects of these complex reactions.

\section{Case presentation}

Treatment of Phoebus, a 14year old boy, started with a frequency of once a week shortly after his hospitalization due to a suicidal attempt by taking pills. He took the pills after some incidents at school where he felt that the others (students and teachers) underestimate him and scorn him. He wanted to see how the others will react to him if they realize that he feels terrible. He had previously written a letter to his parents and had asked that it be read publicly. Immediately after taking the drug he was terrified. When the hospital doctors assured the family that there is no danger to his life and health, Phoebus' speech became almost triumphant when talking about the self-destruction attempt. He felt that it was an extremely successful way to become famous at school and proof that he could defeat death. Both parents say they were not shocked; he did it to attract attention. In fact, they left him alone during the second night in the hospital on the excuse that they wanted to make him feel independent.

Phoebus had experienced a major depressive episode for a year before the suicide attempt. The episode started six months after the death of his maternal grandmother but the symptoms (mainly the loss of pleasure, weight gain, ideas of worthlessness and decreased concentration) deteriorated in the last quarter before the attempt.
Phoebus was tall and overweight. He was the only child of the family and was borne after many traumatic attempts of assisted reproduction. A year before getting pregnant in Phoebus, the mother miscarried in the 7thmonth of pregnancy due to a very rare complication. While carrying Phoebus, the mother showed extreme anxiety from the 7thmonth; she feared the baby would die so the gynecologist gave her a portable cardiotocograph to take home which she used constantly. In the early years of his life, Phoebus presented eating difficulties and was consistently at the lower end of the normal weight range until the age of 6 and he often vomited when he did not want to eat any more. Entering puberty, he started eating more than normal, became overweight and his parents were trying to control his eating.

According to Phoebus, his mother loved him very much and accepted him, while his father rejected him. He described a rather isolated childhood with absolute dependence on the mother and maternal grandmother. He had extreme difficulty to establish a firm friendship relationship with any of his peers. From the age of 1year, he used to sleep in his parents' room alternating with one or the other parent.

His father, 55, assumed he had the role of the evil one in the family, he was hard and absolute, but he felt that his wife did not allow him to impose any limits in the upbringing of the child. His father described Phoebus as immature, competitive and jealous, vengeful, horribly demanding, assertive and loud at home. The mother, 50, satisfied all of Phoebus' favors and he told her everything. She admitted she was very submissive towards the child because there were all these difficulties in child-bearing. Often she hugged, kissed and caressed him as a little kid.

\section{Countertransference reactions during treatment}

The first introductory meeting with Phoebus caused the therapist to feel some degree of dislike. The therapist doubted Phoebus' mental strength and some characteristics of his physical appearance caused him to think of a probable chromosomal disease. He felt somewhat skeptical as to whether he could work with this adolescent while he was anxious lest Phoebus repeat an attempt. Along with the information he received from the assessment of the child psychiatry team during the hospitalization phase, the therapist was forming a first hypothesis in his mind about a quite disturbed teenager, who often moved between omnipotent manic mental states and feelings of helplessness and hopelessness.

During the therapy sessions, the impressions of dislike and unjustified reservation were changed. It seemed that Phoebus, on one hand, was eager to get help from the therapist, on the other, he was terrified by the prospect of dependence on therapy as he hoped to live an "independent" life. Initially, he was very talkative, tempestuous for long periods, cut off from emotions and with a sense of urgency. If the therapist attempted to say something about what Phoebus thought or felt, Phoebus interrupted him and continued to talk about his numerous problems. In countertransference, the therapist felt that both should be very careful because, if they had feelings or talked about them, then, these would become unbearable and the end would be again as bad. On other occasions, the therapist was forced to feel as a very strict judge who did not allow him to speak spontaneously, but obliged him to anxiously find decent words to describe difficult situations: for example, in one instance he could not say the word "bashing" referring to a fight incident with a classmate. The therapist witnessed Phoebus' struggle against an extremely strict sadistic superego to which Phoebus surrendered and to which Phoebus 
identified neglecting his needs and impulses. Phoebus' anxiety was that the treatment made him want and demand more and externalize his aggression openly. If he wanted and demanded more, then, he would attack himself even harder.

As with the suicide attempt, Phoebus conveyed to the therapist the message that each session came too late, that the therapist could not do anything for him because he was not next to Phoebus when the latter really needed him and when, finally, the session day came, the problems had already been solved somehow or had been forgotten. Although, at first level, this seemed to the therapist to reveal an effort by Phoebus to approach the therapist who should have been more available, nevertheless the therapist felt that Phoebus said this to indicate that he was disappointed by the therapist, causing the therapist guilt. The same thing happened when the therapist tried to maintain the sessions' time schedule since Phoebus often failed to come on the agreed time, blamed his mother for the delays and requested that their session be extended. The therapist was ambivalent especially after a long delay and felt he had to give him some minutes; otherwise the therapist would be very strict and indifferent. In retrospect, the therapist thought that the guilt he had to carry was probably the result of the projective identification of Phoebus' guilt on to the therapist, a guilt that stemmed from the assault of Phoebus onto his internal and external objects.

The therapist gradually began to understand his difficulty in maintaining the setting of the therapy. It was apparent to the therapist that he had been feeling a lack of caring for the adolescent or for his life and was defending himself against such feelings by being generous with his time that no one could accuse him of indifference. The unspoken, shared feeling was that it was Phoebus' painful or frightening fantasies of attack or desertion from an internalized indifferent destructive mother who killed her babies. In the external world, Phoebus blamed his mother for his delays, since she was so overprotective of her child - after the several traumatic attempts of assisted reproduction and miscarriages - that she would never allow him out of her sight and never allow him to come to sessions on his own for fear that he might get hurt. For the therapist, one important step in integration of the feeling of indifference was the ability to understand his experience of guilt and his defenses against his feelings of indifference, rather than trying to deny or project these feelings. A necessary prerequisite for this psychological processing was the therapist's feeling that he could have feelings of guilt or indifference without being damaged by them. The therapist at this point chose to interpret Phoebus fear of his own indifference toward an unmotherable, unwanted and hopeless self and his fear of being abolished, attacked or deserted from inside. In this way, the therapy attempted to digest the projection and make it available for re-internalization through the interaction between the therapist and the adolescent.

The situation was also difficult in sessions before the scheduled vacation. There was discussion about death replete with deep feelings of abandonment and loss. The therapist's concern about Phoebus's condition during vacation and the rationalizations that he made about the need for rest and the constraints that reality imposes, probably concealed a kind of aversion to Phoebus who, in turn, counter transferred the feeling of disappointment and anxiety about reuniting with the rejecting therapist - object.

Clearly, on the countertransference level, the therapist faced serious challenges. The therapist's function was influenced either through weakening of the symbolizing capability (transforming external stimuli into psychic elements and functioning according to the role that is assigned to them each time), or through hampering the capability to understand the child's function of phantasy. The impact on the symbolizing capability was expressed mainly in the therapist's altered ability to think within the present situation during the sessions. The therapist showed irrelevant emotional reactions due to a temporarily weakened ability to integrate the urges that came from the patient. In other words, the therapist was presented with a disordered capacity to contain. The therapist was struggling with the game of identifications with the child and the phantasized parents and there was always the risk of his being overwhelmed and losing his capacity to understand object-relationships and transference phenomena. The therapist's supervision in the working-through of these countertransference feelings played a vital catalytic role in this case. The supervisionlike the therapist's individual psychoanalysis - offered the space for reprocessing and containing these reactions related to the adolescent's psychic difficulties.

Three years after the start of treatment (which is still ongoing), Phoebus managed to some extent to discover a sense of energy, positive aggression that allowed him to feel stronger and less terrified of the consequences of his anger. Also, he improved his ability to think more about himself rather than to jump into action. However, he remained vulnerable to loss, disappointment and criticism. He had particular difficulty to place himself emotionally in the relationship with his parents: on one hand, he was experiencing the full availability of his mother that offered him pleasure along with anxiety, fear and guilt in a very tight, overprotective relationship and, on the other hand, he was facing the absolute rejection by his father who left him helpless, under constant judgment, and in despair.

\section{Discussion}

In the case of a suicidal adolescent presented here, the central themes that dominated the treatment over time were-

a. A narcissistic vulnerability, an insecure sense of self and a heightened sensitivity to losses and rejections that led to reduced self-esteem. This reduced self-esteem triggered depressive feelings, anxiety and anger in response to any narcissistic injury.

b. Anger, accusations and envy directed towards others and often led to discontinuation of his interpersonal relationships, confusion about who is to blame and ultimately anger towards himself followed by depressive feelings.

c. Experiences of guilt and shame. Emotions and desires that he experienced as bad or wrong, feeling that his love for others could not outweigh his aggressiveness towards them. Often he resorted to self-criticism and a negative perception of self.

d. Idealized and devaluated expectations for himself and others. Abrupt transitions between the two states often led to frustration, anger towards self and others.

e. Defensive means against painful feelings, especially the projection that led to a recurring sense of a hostile world and the splitting that did not allow his energy and aggression to be integrated into the development of his personality.

Regarding adolescent psychoanalytic psychotherapy, it is noteworthy that developmental characteristics create specific preconditions for the emergence of intense countertransference reactions. Emotions and transference movements alternate rapidly even during the same session; thus, the therapist is invited to go from one extreme to the other in order to emotionally contain the adolescent. 
Acting out - a characteristic of the adolescent developmental stagemanifests naturally in the therapeutic relationship and challenges the therapist at the countertransference level. Devaluation of parents and authority, another characteristic of adolescence, also arises in the therapeutic relationship. Defying the therapist's ability and utterances is very common and understandable; however, this does not negate the challenge to the therapist. The game of control regarding limitsetting is endless at all levels.

Countertransference, when not recognized, creates the risk of being expressed in damaging or potentially catastrophic manner towards the teenager. The therapist, who has the megalomaniac expectation to be able to offer to the teenager the corrective emotional experiences that he never received as a child, will be disappointed when the patient does not accept this kind of empathic therapy or when the patient devours this acceptance and requires more and more time and energy from the therapist. Possible consequences of a not recognized countertransference (either positive or negative) is the aggressiveness towards the patient.

Maltsberger and Buie $^{22}$ identified five different defensive moves to which therapists may resort when they feel negative countertransference feelings. The first is the repulsion of hatred that can manifest itself as a feeling of boredom or fatigue. The second is the shift in countertransference hatred towards the self, so the therapist masochistically discredits himself and feels inadequate. The third type of defensive move is reaction formation. Here, the therapist occupies himself excessively with the care of the patient and he experiences intense anxiety and a sense of urgency to help the patient. The fourth defense is projection. In this case, the therapist projects on to the patient his own intense aggressive feelings. Here, the therapist overemphasizes the likelihood that the patient commit a suicide attempt, even when the data do not support that there is a significant risk. The last type of defense is distortion and denial of reality that certifies counter transference hostility. Often this occurs through the discrediting of the patient as helpless or untreatable. In this case, the therapist may be experiencing indifference, pity or anger; nevertheless, he lacks empathy for the patient. Here, often the treatment is terminated prematurely or the patient is referred elsewhere.

Given that the technique of interpretation is not always available in such situations, the main goal is to use these counter transference responses in the service of the adolescent's psychotherapy by understanding the adolescent's internal reality, resistance, and experience, as well as the intensity and nature of external experiences within the family. Psychoanalytic psychotherapy, apart from enhancing interpersonal skills and adolescent's support networks, should focus on improving the quality of object relations, working through actual and fantasized losses, modifying less adaptive defenses, and containing the projective identification of primitive introjects.

The psychodynamic approaches can contribute significantly to the diagnostic access and the treatment of adolescents after a suicide attempt. ${ }^{3}$ Research supports the role of dynamic and developmental factors in understanding suicidal patients. ${ }^{5,11,26}$ Exploring the transfer and processing of counter transference reactions enables the therapist to approach those unconscious - but very strong - factors that contribute to suicidal impulses. These psychodynamic factors can create a therapeutic means through which we may offer the patient some relief from his discomfort and may enable us to evaluate more realistically situations that induce self-destructive tendencies.

\section{Acknowledgments}

None.

\section{Conflicts of interest}

Author declares there are no conflicts of interest.

\section{Funding}

None.

\section{References}

1. Brent DA, Baugher M, Bridge J, et al. Age and sex-related risk factors for adolescent suicide. J Am Acad Child Adolesc Psychiatry. 1999;38(12):1497-1505.

2. Gould MS, King R, Greenwald S, et al. Psychopathology associated with suicidal ideation and attempts among children and adolescents. $J$ Am Acad Child Adolesc Psychiatry. 1998;37(9):915-923.

3. American Academy of Child and Adolescent Psychiatry. Practice parameter for the assessment and treatment of children and adolescents with suicidal behavior. J Am Acad Child Adolesc Psychiatry. 2001;40(7 Suppl):24S-51S.

4. Foley DL, Goldston DB, Costello EJ, et al. Proximal psychiatric risk factors for suicidality in youth: The Great Smoky Mountains Study. Arch Gen Psychiatry. 2006;63(9):1017-1024.

5. Rodgers RF, van Leeuwen N, Chabrol H, et al. An exploration of the role of defensive psychopathology in adolescent suicidal ideation and behavior. Bull Menninger Clin. 2011;75(3):236-253.

6. Freud S. Mourning and Melancholia. In: Strachey J (Ed.), The standard edition of the complete psychological works of Sigmund Freud. Hogarth Press, London. 1997. p. 237-258.

7. Freud S (1922) Beyond the pleasure principle. In: Strachey J (Ed.) The standard edition of the complete psychological works of Sigmund Freud. Hogarth Press, London, p. 1-64

8. Freud S. Three essays on the theory of sexuality. In: Strachey J (Ed.) The standard edition of the complete psychological works of Sigmund Freud. Hogarth Press, London. 1905. p123-245.

9. Freud S. Insticts and their vicissitudes. In: Strachey J (Ed.) The standard edition of the complete psychological works of Sigmund Freud. Hogarth Press, London. 1915. p. 109-140.

10. Freud S. The economic problem of masochism. In: Strachey J (Ed.) The standard edition of the complete psychological works of Sigmund Freud. Hogarth Press, London. 1924. p 155-170.

11. Chabrol H, Van Leeuwen N, Rodgers RF. Exploratory study of the relations between sadistic traits and suicidality in a nonclinical sample of adolescents. Bull Menninger Clin. 2011;75(3):224-235.

12. Freud S. The Ego and the Id. In: Strachey J (Ed.) The standard edition of the complete psychological works of Sigmund Freud. Hogarth Press, London. 1923. p.1-66.

13. Fenichel O. The psychoanalytic theory of neurosis. Norton, New York, USA. 1945. p.705

14. Heider I. Suicide attempts in children and adolescents. Br J Psychiatry. 1968;114(514):1113-1134

15. Rado S. Psychodynamics of depression from the etiologic point of view. Psychosom Med. 1951;13(1):51-55.

16. Kohut $\mathrm{T}$. The restoration of the self. University of Chicago Press, Chicago, USA. 1977. p.368. 
17. Baumeister RF. Suicide as escape from self. Psychol Rev. 1990;97(1):90-113.

18. Kernberg O. Borderline conditions and pathological narcissism. Aronson, New York. 1975.

19. Klein M. A contribution to the psychogenesis of manic-depressive stages. Contributions to psychoanalysis 1921-1945. Hogarth Press, London. 1934. p.228-310.

20. Winnicott DW. Collected papers: Through pediatrics to psychoanalysis. Tavistock Publications, London. 1958.

21. Winnicott DW. The theory of the parent-infant relationship. Maturational processes and the facilitating environment. Basics Books, New York. 1960. p.37-55.

22. Maltsberger JT, Buie DH. Countertransference hate in the treatment of suicidal patients. Arch Gen Psychiatry. 1974;30(5):625-633.

23. Asch SS. Suicide and the hidden executioner. Int Rev Psycho-Anal. 1980;7:51-60.

24. Ogden TH. On projective identification. Int J Psycho-Anal. 1979;60(Pt 3):357-373.
25. Chance SE, Reviere SL, Rogers JH, et al. An empirical study of the psychodynamics of suidice: A preliminary report. Depression. 1996;4(2):89-91.

26. Kaslow NJ, Reviere SL, Chance SE, et al. An empirical study of the psychodynamics of suicide. $J$ Am Psychoanal Assoc. 1998;46(3):777-796.

27. King RA, Apter A. Psychoanalytic perspectives on adolescent suicide. Psychoanal Study Child. 1996;51:491-511.

28. Freud A. Comments on aggression. Int $J$ Psycho-Anal. 1972;53(2):163-171.

29. Giovacchini PL. Countertransference and the severely disturbed adolescent. Adolesc Psychiatr. 1985;12:449-467.

30. Brandell J. Countertransference phenomena in the psychotherapy of children and adolescents. In: Brandell J (Ed.) Countertransference in Psychotherapy with Children and Adolescents. Jason Aronson, Inc., Northvale, New Jersey, USA. 1992. p. 215-234. 